\title{
Nurses' attitudes and behaviors during bachelor of nursing students' clinical learning experiences
}

\author{
Shauna L. Keil, Kathleen R. Ward \\ Department of Nursing, Fort Hays State University, Hays, KS, USA
}

Received: September 27, 2019

Accepted: October 28, 2019

Online Published: November 4, 2019

DOI: $10.5430 /$ jnep.v10n2p24

URL: https://doi.org/10.5430/jnep.v10n2p24

\begin{abstract}
Objective: This study aimed to examine the nurse-student relationship during clinical learning experiences.

Methods: Students at all levels of a Bachelors nursing program completed the Nursing Student Perception of Civil and Uncivil Behaviors tool (NSPCUB) after clinical experiences during each semester over one calendar year at a small Midwestern university. The tool included 12 items, four demographic questions, and two qualitative questions.

Results: A total of 302 surveys were returned. The majority of surveys were completed by second semester students on a medical-surgical unit. The majority of students had positive experiences. Night shift nurses had a significantly higher mean on two variables. There was also statistical significance between second and third semester students on two variables. There were no statistical differences between units and hospitals. Student's comments were mostly positive, though negative experiences still occurred.

Conclusions: Nurses can positively impact student's clinical learning experiences. Students have both positive and negative experiences in the clinical setting. Several positive themes were identified including role modeling, skill acquisition/teaching, communication and critical thinking development. Negative themes also occurred including rudeness, feeling ignored and inappropriate behavior. Further research is recommended.
\end{abstract}

Key Words: Nursing student, Student perceptions, Clinical learning environment

\section{INTRODUCTION}

The clinical learning environment (CLE) is a vital component of nursing education. Clinical learning environments provide real-world experiences to facilitate student learning. The CLE provides opportunities for skill development, socialization, and career choice decision-making. ${ }^{[1]}$ In addition, the CLE provides the opportunity to apply and analyze content learned in the classroom and simulation to real patient care.

The American Nurses Association's Code of Ethics for Nurses with Interpretive Statements states nurses are obligated to "create an ethical environment and culture of civility and kindness, treating colleagues, coworkers, employees, stu- dents, and others with dignity and respect (p.4)." "2] Student learning in the clinical environment is dependent on respect, consideration, and supportive civility. Positive CLEs have the greatest influence on retention, while negative experiences are associated with stress and attrition. ${ }^{[3]}$

Clinical learning environments can be stressful for both the nursing student and the nurse. Ultimately, this stress may result in lapses of civility. Various stressors have an impact on staff nurses including attitudes and motivation of the student, increase in workload, length of experience as a nurse, and workforce shortages. ${ }^{[4]}$ Some studies found that there were both positive and negative aspects of nursing students' con-

*Correspondence: Shauna L. Keil; Email: slkeil@ fhsu.edu; Address: Department of Nursing, Fort Hays State University, Hays, KS, USA. 
tributions to clinical practice. Registered nurses mentioned enhancement of their professional development as a positive attribute and increased demands on time and workload as a negative consequence. ${ }^{[5]}$

Students identify assignments, faculty and staff, and peers as top stressors in the clinical learning environment. ${ }^{[6]}$ Another study found students generally had positive clinical experiences in spite of the fact that mentors have little time to teach, and sometimes use the students simply as an extra pair of hands. ${ }^{[7]}$ Examples of nursing behaviors that lead to negative clinical experiences include avoidance and/or isolation, oppression, withholding information, humiliation, and poor role modeling. ${ }^{[8,9]}$ Students also report negative clinical experiences when assigned jobs below his or her expected learning and skill level. ${ }^{[10]}$ Two common behaviors in the CLE include covert criticism and shaming. ${ }^{[11]}$ Nurse-student interactions that include shaming have been found to hinder communication and leave students feeling intimidated and insecure. Ultimately, these behaviors can comprise the quality of care the client receives and affect career choices.

Duffy's Quality Caring Model served as the framework for this study. According to this model, relationships are the nucleus of therapeutic care. Positive relationships are centered on respect, faith, hope, sharing information, thoughts, feelings, and concerns. ${ }^{[12]}$ According to Duffy's Model, all relationships within the clinical environment must be considered as they have the potential to impact health outcomes for the client. This includes the nurse's relationship between the patient and family as well as the healthcare team. When considering the student-nurse relationships, those based on encouragement, caring, reassurance, and collaborative problemsolving have the potential to provide students with positive clinical experiences. When students feel welcomed and valued, not only is learning enhanced but so is the quality of care for patients and families. ${ }^{[13]}$

The Nursing Student Perception of Civil and Uncivil Behaviors (NSPCUB) tool was developed in 2015. ${ }^{[14]}$ The NSPCUB is a 12 item questionnaire designed to measure the nursing student experience. It has a 4-point Likert scale ranging from "strongly disagree" to "strongly agree". The questionnaire was modified to ascertain demographic data that included semester of program, hospital or clinical site, unit, and shift. Two open-ended questions were also included to provide qualitative data. These questions were: "Were there any experiences on this unit today that made you feel welcomed as part of the patient care team?" and "Were there any experiences on this unit today that made you feel ignored, unwanted, or disrespected?"

The NSPCUB instrument consists of four items for each construct (mutual respect, guided participation, and student centeredness). The Cronbach's alpha score for the tool and its constructs was greater than 0.70. Reliability testing of the NSPCUB revealed a Cronbach's alpha for the entire instrument of .927 indicating high reliability of measuring incivility in the CLE. ${ }^{[14]}$ The Cronbach's alpha for this study was determined to be .937 . Few studies have utilized this tool. One study that did utilize it focused on a pre-post intervention survey in a pediatric magnet hospital. ${ }^{[16]}$

\section{METHODS}

The objective of this study was to identify the nurse-student relationship during clinical learning experiences and the impact it had on the experience, student learning, performances, and future career choices. The study was completed at a small Midwestern university Bachelor of Science nursing program. This is a four-year program, with the first two years being dedicated to general education and pre-requisite classes, and the last two years (four semesters) dedicated to specific nursing classes. Thirty students are admitted in both the spring and fall semesters leading to a total of 100-120 students in the program at one time (with attrition). The vast majority of students are females who are 22-25 years old.

Clinical experiences occur in all four semesters of the nursing courses, and include a variety of experiences. Faculty-led, preceptor, and observation modalities are used throughout all clinical courses. During faculty-led clinicals, one faculty member supervises up to ten students at the clinical site per state regulations. During preceptored clinical experiences, a staff nurse serves as a preceptor to one student throughout his or her shift. Finally, during observational experiences, the student follows one staff member for all or part of a shift. The majority of clinical experiences are faculty-led at the junior level, while more preceptored clinicals are more prevalent at the senior level. In order to understand the clinical experiences of this university, it is imperative to note the rural setting of the university. There is only one hospital within the community. Consequently, this is where a majority of clinical hours are completed. In order to ensure students are prepared to work in any setting-from rural to metropolitan - travel is required. Students and faculty travel three hours for clinical opportunities at Level-I trauma centers. Conversely, students must also participate in clinicals at critical access hospitals throughout the area.

In the first semester of the junior year, students focus on caring for one medical-surgical patient on a 46 bed unit at the local hospital. Faculty assist students in medication administration, and facilitate the clinical experience. In the second semester of the Junior year, students begin by caring for one patient, then progress to caring for two patients. Second- 
semester Junior level students also have the opportunity for a preceptored experience where they work directly with one nurse caring for a full patient load. There are also experiences in specialty units including ambulatory, the operating room, post anesthesia care unit, hospice, outpatient oncology, outpatient radiation, and psychiatric units. In these experiences, students work directly with the nurse in either a preceptor or observation experience. The third semester focuses on specialty clinical in Obstetrics and Pediatrics. Experiences take place in home health, a local hospital, and a Level I trauma center. While these experiences are predominantly faculty-led, the student generally works directly with one staff nurse for an entire shift. The fourth semester focuses on critical care and leadership and management. Clinical experiences include rural hospitals, opportunities to care for a full assignment on an acute care medical-surgical unit, and critical care units. Students in their final semester complete a capstone on a unit of their choice where they work directly with a nurse at various hospitals throughout the state. The clinical in program is limited to $15 \%$ being preceptored hours, meaning faculty is working directly with students the majority of the time.

The study design was a descriptive study that utilized selfreported survey data. Surveys were given over the course of one calendar year from January 2018 to December 2018. Students had the option to complete the NSPCUB after clinical experiences. Unique to this study was the incorporation of collecting data from a variety of clinical facilities, shifts (days versus nights), hospital units, and level of nursing students. Shifts varied in length depending on the type of clinical experience and semester of student. First and second semester students had shorted clinical experiences varying from 4 to 8 hours. Third and fourth semester students had longer experiences with the majority being 6 to 12 hour shifts. Students were primarily on dayshift which was classified as any hours between $7 \mathrm{am}$ and $7 \mathrm{pm}$. Night shift was classified as any hours from $7 \mathrm{pm}$ to $7 \mathrm{am}$. Students generally did 4 to 6 hours on night shift and rarely completed a full 12 hours on night shift.

IRB approval was granted through the university Institutional Research Board. Students were invited to participate via email with the survey attached. Participation was voluntary and consent was implied by completing the questionnaire. Inclusion criteria included being a nursing student completing clinicals and willingness to complete the survey. Once the surveys were complete, participants placed them in a sealed envelope and sent them to the primary investigator through departmental mail. Self-addressed envelopes were located in the nursing department and were available for all students to take. The envelopes were not designated as research and were identical to envelopes used for a variety of other purposes. The envelopes had free postage and could be returned to the front office staff or mailed through the US postal system. If turned into the front office, the envelopes were placed directly into the primary investigator's faculty mailbox but the office staff would be unaware of what was inside the envelope. The researchers did not receive the completed surveys directly from any students to ensure anonymity. Staff nurses and preceptors were not aware of the research to prevent coercion. Permission to utilize the NSPCUB was obtained from the authors of the original study.

There survey had two open-ended questions, "Were there any experiences on the unit that made you feel welcomed as part of the patient care team?" and "were there any experience on this united that made you feel ignored, unwanted or disrespected?" These allowed the students to provide additional qualitative data regarding the clinical experience.

Due to the rural location of the university, students completed clinicals in a variety of facilities and geographic locations. Clinical sites varied widely; sites included Level I, II and III Trauma Centers, Critical Access Hospitals, and Psychiatric hospitals. Within the hospital, the units included medicalsurgical, intensive care, emergency department, orthopedics, operating room, ambulatory, post-anesthesia care unit, psych, long term care, obstetrics, pediatrics and neonatal intensive care. Shifts included both day and night shifts. Night shift experiences were generally limited to evenings. University faculty served as the clinical educators. Unit nurses did interact with students to provide care and varying levels of support depending on clinical and semester of student. Only $15 \%$ of experiences were primarily led by a unit nurse without a clinical educator on site.

Data analysis was conducted using SPSS version 23 to obtain descriptive statistics, independent t-test, and ANOVA tests. Reverse coding was used on questions 3, 6, 7, and 9. Descriptive statistics including frequencies, percentages, mean, and standard deviation were used to determine the distribution of the variables. Independent t-test and ANOVA was conducted to determine the significant mean difference between shift, semester, hospital, and unit.

\section{RESULTS}

Students completed 302 surveys over year long data collection process. Surveys were completed from students in each semester of the junior and senior years of the nursing program. The majority of the results were from the second semester Junior level students (39.4\%). Most students completing the survey were in clinical during the day $(82.5 \%)$. The most common site was the local hospital on a medical 
surgical unit.

Table 1. Demographics

\begin{tabular}{|c|c|c|c|}
\hline & & Frequency & $\%$ \\
\hline \multirow{4}{*}{ Class } & First Semester & 54 & 17.9 \\
\hline & Second Semester & 119 & 39.4 \\
\hline & Third Semester & 85 & 28.1 \\
\hline & Fourth Semester & 44 & 14.6 \\
\hline \multirow{2}{*}{ Shift } & Day (Hours between $7 \mathrm{a}$ to $7 \mathrm{p}$ ) & 249 & 82.5 \\
\hline & Night (Hours between $7 p$ to $7 a$ ) & 53 & 17.5 \\
\hline \multirow{5}{*}{ Hospital } & Level 3 Trauma Center & 204 & 67.5 \\
\hline & Level 2 Trauma Center & 11 & 3.6 \\
\hline & Level 1 Trauma Center & 80 & 26.5 \\
\hline & Rural & 5 & 1.7 \\
\hline & Mental Health & 2 & .7 \\
\hline \multirow{14}{*}{ Unit } & Medical/Surgical & 150 & 49.7 \\
\hline & Obstetrics & 44 & 14.6 \\
\hline & NICU & 26 & 8.6 \\
\hline & Ambulatory & 7 & 2.3 \\
\hline & OR & 7 & 2.3 \\
\hline & PACU & 6 & 2.0 \\
\hline & Intensive Care Unit & 17 & 5.6 \\
\hline & Emergency Room & 5 & 1.7 \\
\hline & Pediatrics & 17 & 5.6 \\
\hline & Psychiatric & 6 & 2.0 \\
\hline & Hospice & 6 & 2.0 \\
\hline & Orthopedic & 7 & 2.3 \\
\hline & Long term care & 4 & 1.3 \\
\hline & Total & 302 & 100.0 \\
\hline
\end{tabular}

The survey consisted of twelve quantitative questions plus two additional qualitative questions. Eight responses were positively themed and four were negatively themed. The highest rated question was the "RN acknowledged my introduction" and the "RN was approachable." The lowest rated question was "RN talked to me about ways to improve my nursing care." This could be related to several factors including the workload of the nurse and perception of their role though theme found was critical thinking development. The highest rated negative statement was the "RN during my clinical shift." This could be related to the students frequently caring for one patient whereas the nurses had a full patient load or the general work load of the nurses. It is noted that all negative questions were rated low.

Independent $t$-test was conducted to determine the statistical significant difference between shift and nursing variables. Questions 3, 6, 7 and 9 were reversed before analysis.

On item 2 "the RN included me in his or her decision making process," night shift nurses had a statistically significant higher mean $($ mean $=3.5472)$ as compared to the day shift nurses $($ mean $=3.257$ ) (mean difference $=0.29, t=2.445$, $p<.050$. There was also a statistical significance between night shift nurses (mean $=4.0)$ and day shift nurses (mean $=3.7028$ ) (mean difference $0.29719, t=2.673, p<.01$ ) on item 3 "RN was disrespectful towards me." This question was reverse coded, meaning night shift was rated as "never" being disrespectful towards nursing students.

Table 2. Survey Results

\begin{tabular}{llll}
\hline Item Code & Question & Mean & Standard Deviation \\
\hline NS1 & 1. RN was approachable & 3.5927 & .63900 \\
NS2 & 2. RN included me in his or her nursing decision making process & 3.3079 & .79106 \\
NS3 & 3. RN was disrespectful to me & 1.3013 & .83044 \\
NS4 & 4. RN invited me to actively participate in my patient's care & 3.5132 & .71863 \\
NS5 & 5. RN acknowledge my introduction & 3.6026 & .59432 \\
NS6 & 6. RN ignored me during my clinical shift & 1.3510 & .63349 \\
NS7 & 7. RN did patient care without including me & 1.5861 & .77601 \\
NS8 & 8. RN helped calm my anxieties & 3.2086 & .81892 \\
NS9 & 9. RN embarrassed me in front of others & 1.2517 & .88711 \\
NS10 & 10. RN went out of his or her way to meet my learning needs. & 3.3311 & .85276 \\
NS11 & 11. RN talked to me about ways to improve my nursing care & 3.1093 & .97373 \\
NS12 & 12. RN encouraged me to ask questions & 3.2715 & .9464 \\
\hline
\end{tabular}

ANOVA test was conducted to determine the mean difference between class, hospital, and nursing variables. The analysis reveals a statistical significant difference between second semester and third semester students on item S6 "RN ignored me during my clinical shift" $(\mathrm{F}=2.966, p<.05$ .031)); and item 11 "RN talked to me about ways to improve my nursing care" $(\mathrm{F}=3.355, p<.05$ ( .019$)$. The majority of second semester clinicals take place in medical-surgical 
units whereas third semester students do specialty clinical compared to larger medical-surgical units. There is no stain obstetric and pediatrics units. Nurses on specialized units often have more individualized interactions with students tistical significant difference between hospital and nursing variables with $p>.05$.

Table 3. Independent t-test between shift and nursing variables

\begin{tabular}{|c|c|c|c|c|c|c|c|}
\hline Item Code & Shift & $\mathbf{N}$ & Mean & SD & Mean difference & $t$-value & $p$-value \\
\hline \multirow{2}{*}{ NS1 } & Day & 249 & 3.5743 & .65647 & -.10495 & -1.086 & .278 \\
\hline & Night & 53 & 3.6792 & .54679 & & & \\
\hline \multirow{2}{*}{ NS2 } & Day & 249 & 3.2570 & .80710 & -.29014 & -2.445 & .015 \\
\hline & Night & 53 & 3.5472 & .66697 & & & \\
\hline \multirow{2}{*}{ NS3 } & Day & 249 & 3.7028 & .64134 & -.29719 & -2.673 & .008 \\
\hline & Night & 53 & 4.0000 & 1.07417 & & & \\
\hline \multirow{2}{*}{ NS4 } & Day & 249 & 3.4819 & .73553 & -.17845 & -1.646 & .101 \\
\hline & Night & 53 & 3.6604 & .61842 & & & \\
\hline \multirow{2}{*}{ NS5 } & Day & 249 & 3.5823 & .60429 & -.11578 & -1.289 & .198 \\
\hline & Night & 53 & 3.6981 & .54012 & & & \\
\hline \multirow{2}{*}{ NS6 } & Day & 249 & 3.6265 & .65459 & -.12821 & -1.340 & .181 \\
\hline & Night & 53 & 3.7547 & .51537 & & & \\
\hline \multirow{2}{*}{ NS7 } & Day & 249 & 3.4137 & .76831 & -.00144 & -.012 & .990 \\
\hline & Night & 53 & 3.4151 & .81886 & & & \\
\hline \multirow{2}{*}{ NS8 } & Day & 249 & 3.1727 & .84618 & -.20467 & -1.657 & .099 \\
\hline & Night & 53 & 3.3774 & .65710 & & & \\
\hline \multirow{2}{*}{ NS9 } & Day & 249 & 3.8153 & .82673 & -.05266 & -.452 & .651 \\
\hline & Night & 53 & 3.8679 & .39408 & & & \\
\hline \multirow{2}{*}{ NS10 } & Day & 249 & 3.2932 & .87436 & -.21626 & -1.682 & .094 \\
\hline & Night & 53 & 3.5094 & .72384 & & & \\
\hline \multirow{2}{*}{ NS11 } & Day & 249 & 3.0843 & .97391 & -.14208 & -.964 & .336 \\
\hline & Night & 53 & 3.2264 & .97352 & & & \\
\hline \multirow{2}{*}{ NS12 } & Day & 249 & 3.2410 & .94515 & -.17413 & -1.217 & .225 \\
\hline & Night & 53 & 3.4151 & .94937 & & & \\
\hline
\end{tabular}

Table 4. ANOVA test between semester hospitals and nursing variables

\begin{tabular}{|c|c|c|c|c|}
\hline & \multicolumn{2}{|c|}{ Semester } & \multicolumn{2}{|c|}{ Hospital } \\
\hline & $\mathbf{F}$ & Sig. & $\mathbf{F}$ & Sig. \\
\hline NS1 & .261 & .853 & .737 & .568 \\
\hline NS2 & 1.994 & .115 & .722 & .578 \\
\hline NS3 & .602 & .614 & .694 & .597 \\
\hline NS4 & 2.605 & .052 & .961 & .429 \\
\hline NS5 & 1.475 & .221 & .877 & .478 \\
\hline NS6 & 2.996 & .031 & 2.001 & .094 \\
\hline NS7 & 1.490 & .217 & 1.457 & .215 \\
\hline NS8 & .248 & .863 & .231 & .921 \\
\hline NS9 & .428 & .733 & .779 & .539 \\
\hline NS10 & 1.737 & .159 & .955 & .432 \\
\hline NS11 & 3.355 & .019 & 1.741 & .141 \\
\hline NS12 & 2.059 & .106 & 2.041 & .089 \\
\hline
\end{tabular}

\subsection{Positive themes}

Students expressed many positive themes to the survey question 'were there any experiences that made you feel welcomed as part of the patient care team.' Several positive themes were noted by students' comments including role modeling, skill acquisition/teaching, communication and critical thinking development. Positive themes were the majority of comments expressed by students and correlated with the quantitative data.

\subsubsection{Role modeling}

The lack of role modeling prevalent in much of the literature was not identified in this study. The majority of the students in this study found the nurses to be excellent role models. Numerous qualitative comments regarding the nurse as a positive role model were received.

"My nurse was amazing. The environment was 
very welcoming and involved me in everything. There was a time the nurse stopped and realized I wasn't in the room so she came and found me." "The nurse stated the day by including me in report and she also let me pick the goal we had for each of the patients we took care. She also sat down, made charts for me and helped me learn for a test." She tried to include me as much as possible with patient care.

"She (the nurse) cared greatly for each of her patients; all of the interactions I witnessed were patient centered and kind. This nurse is the type of nurse I want to be as she was kind to everyone as well prompt and gentle with her care."

"The nurse was very friendly and went out of her way to make me feel comfortable at clinical."

"I did not realize the impact a good nurse can have on a clinical day."

"Night shift is so much better than dayshift. More quiet and less people. Super encouraging nurses" "The RN talked to me a lot. She is awesome. The nurses are helpful and approachable."

"I felt included and welcomed on the floor. This was a great clinical experience."

"She made herself very approachable to ask questions or help if needed. She actually acknowledged my presence unlike some nurses I've had in the past."

\subsubsection{Skill Acquisition/Teaching}

Another area of strength identified in the qualitative data was in the area of skill acquisition and the nurse's role to teach.

"Not only did I have a great time with my patient, I have had a great time with my nurse'; having a nurse that includes you in your patients' care makes a huge difference on how your clinical experience will be."

"She taught me ways on how to better my skills and time management."

"This clinical assure me that I want to work in the SICU after graduation."

"She asked me questions on medications and interventions being performed as well as went out of her way to find answers for my questions."

"My nurse was very informative and taught me more than I ever learned in class."

"These nurses were the only nurses willing to help or even acknowledge me so it really made a difference in my attitude for the day and my learning opportunities."

\subsubsection{Communication}

Another area of strength identified in the qualitative data was in the area of communication between the nurse and student.
"She gave me constructive feedback on improve- ments that could be made and what I did well on."
"Good communication!"
"My included me in discussion about patients."
"She always communicated with me."

\subsubsection{Critical Thinking Development}

A final area of strength noted in the study was the development of critical thinking.
"She asked my opinion, listened to my sugges- tion and took them; acknowledge my critical thinking and clinical reasoning. She gave me advice and included time in decisions and dis- cussions."
"The night shift nurse was very informative. Not only did she take the time to explain the rea- soning behind everything she was doing, but she made sure that all of my questions were an- swered."
"Gave me some great questions and cases to as- sess my knowledge and challenge my critical thinking."

\subsection{Negative themes}

Students provided feedback on if there were any experiences on this united today that made you feel ignored, unwanted or disrespected. Negative themes found included rude behavior by nurses, students feeling ignored and inappropriate behavior by nurses. Negative feedback from students was not as common as positive feedback but did still occur in the clinical setting.

\subsubsection{Rude}

Participants revealed they were subjected to rude behavior when sharing qualitative comments.

"She was rude and shut down questions with eye rolls."

"Every time I would ask a question she would jump down my throat with a reply "I don't know, go ask your instructor."

"Whenever I asked my nurse questions she seemed annoyed." 
"Talked about how she hated students that asked questions."

\subsubsection{Ignored}

In addition, qualitative comments revealed students were subjected to being ignored during clinical experiences.

"My nurse completely left me out of report and did report at the nurses station on the back wall, when she could clearly see I was standing there waiting on her."

"My preceptor made me feel horrible. She ignored me the whole time."

"They didn't seem to want us here or are interested in our learning experiences."

"Made me feel like I was a burden all day."

"I could just tell my nurse absolutely did not want a student and she made it obvious."

\subsubsection{Inappropriate behavior}

As noted in previous studies, this study did identify inappropriate behaviors by staff nurses.

"Awful experience and will probably never forget it."

"The charge nurse asked if anyone was willing to have a student follow them for the day. They all said no have you checked with . . . ?"

"When I first arrived, the night nurse went into my patients without acknowledging me. I followed her into the room and asked to help her and she laughed and told me and she didn't need help."

"I felt as though the nurse wasn't passionate about her job and would frequently walk off to complete nursing care without me. I wouldn't want this preceptor or this clinical experience again."

"She was just very busy. More there to go get things for the nurse."

"Made me feel stupid for asking questions or trying to explain things."

"The unit manager informed nurse was going to have a student with her and she rolled her eyes and said "Really?" This started me off feeling really unwanted."

\section{Discussion}

This study aimed to explore the nurse-student relationship during clinical learning experiences and the impact those experiences have on student learning, performances, and future goals. Findings of the qualitative portion of the study identified both positive and negative themes. A previous study had indicated the majority of the students reported lack of skill performance opportunities. ${ }^{[9]}$ However, in this study skill acquisition was identified as strength that resulted in a positive learning environment. Students frequently mentioned that the nurse provided opportunities for them to perform skills. Other positive themes included role-modeling, effective communication, and developing critical thinking.

The authors of the NSPCUB utilized in a pediatric magnet hospital with pre-post intervention survey. ${ }^{[16]}$ This study showed scores of above 3 for each positive on the NSPCUB scale. In comparison, this study done without intervention and multiple sites scored higher all eight positive survey statements then the pediatric hospital study. In this study, the third semester which only utilized pediatrics and obstetric clinical sites was ranked lower than other semesters. Further research is needed to identify the differences in these clinical situations. These are higher risk populations where students may be limited in hands on experiences which may affect overall perceptions.

The findings in this study were similar to a study that revealed the perception of the CLE to be more positive than negative. ${ }^{[6]}$ Unfortunately, negative experiences still exist. Negative themes identified in this study included rude behavior, inappropriate behavior, and avoidance. Within the clinical setting, these behaviors are identified as incivil. ${ }^{[8]}$ Many of these same themes have been identified in previous studies, including lack of respect, showing annoyance, not answering students' questions, and complaining about teaching students. Incivility in the learning environment negatively affects the learning process by reducing academic motivation, which in turn interrupts the learning process.

Incivility and disrespect are linked to poor patient outcomes, employee dissatisfaction and increased turnover rates. ${ }^{[15]}$ It is necessary to create a culture of civility to improve outcomes, employee satisfaction and retention. This should start with nursing students. A positive clinical experience can help recruit future nurses, decrease turnover and improve patient outcomes. It is vital to be aware that the implications of perceived incivility on behalf of a student extends far beyond the clinical experiencing. ${ }^{[16]}$

\subsection{Limitations}

Limitations of this study include the small sample size, the use of a convenience sample from one nursing program, and collecting data over only two semesters. Specific demographics of age and gender were not collected. Response rates varied between semesters. The response rate is difficult to 
surmise due to the varied amount of students in each semester and clinical per student. The study was initiated to see what students felt and experienced in the clinical setting. No interventions were initiated during data collection to improve student perceptions. The study included only undergraduate students in inpatient settings and may not be generalized to other settings or other programs. The NSPCUB has not been widely utilized in other studies. Previous studies focused on one hospital pre and post intervention comparison. More research is needed.

\subsection{Recommendations for future research}

Future research includes evaluating nurses' attitudes toward working with nursing students and the implementation of an intervention provided to students prior to clinical experiences. The interventions would aid students in recognizing nurse stressors that may have an impact on behaviors and attitudes (e.g., workload, years of experience, and personal life issues) during a given CLE. Few studies focus on differences in units and shifts and nursing students' perceptions. Further study could provide more data to determine the differences in units or hospitals. Expanding clinical to evening and night shifts may not only help solve the challenge of securing clinical experiences, but could potentially lead to better student experiences. Research could also focus on Associate nursing student versus Bachelors nursing student's perceptions of clinical experiences. The main clinical site is evenly divided between Associate and Bachelor degree prepared nurses.

Students and staff nurses may not be aware of the each other's roles and responsibilities. Nurses were provided education on student goals for clinical through a video prior to this study. After this study, instructors visited unit meetings to discuss the difference between the types of clinicals on the unit and expectations for students in different semesters. This allowed floor nurses to communicate questions, concerns and suggestions to clinical nurse educators. Students were made aware of the role of the nurse and the factors that may play into the clinical experience. Future study with interventions is warranted. Research on nurses' perceptions of students may also be beneficial prior to more interventions and reassessment.

\section{Conclusion}

"Civility is an authentic respect for others that requires time, presence, willingness to engage in genuine discourse and intention to seek common ground. Civility matters because treating one another with respect is requisite to communicate effectively, building community and creating highfunctioning team".[17] This study demonstrates students experienced an overall more positive than negative learning environment. There were indications of negative experiences; however it was not to the level experienced in previous studies. This could be an indication that efforts to create a more positive work environment for nurses, students, healthcare team members, and especially patients and their families are making a difference.

\section{ACKNOWLEDGeMENTS}

The authors would like to thank the students who complete the survey and the nurses who serve as preceptors for nursing students.

\section{CONFlicts OF InTEREST Disclosure}

The authors declare that there is no conflict of interest.

\section{REFERENCES}

[1] Ion R, Smith K, Dickens G. Nursing and midwifery students' encounters with poor clinical practice: a systemic review. Nurse Educ Pract. 2017 Mar; 23: 67-75. PMid:28259633 https ://doi .org/10.101 6/j.nepr.2017.02.010

[2] American Nurses Association. Code of ethics for nurses with interpretative statement [Internet]. Silver Spring (MD): [revised 2015 Jan, cited 2019 Sept 25] Available from: https : //www . nursingw orld.org/practice-policy/nursing-excellence/ethics /code-of-ethics-for-nurses/coe-view-only/

[3] Crombie A, Brindley J, Harris D, et al. Factors that enhance rates of completion: what makes students stay? Nurse Educ Today. 2013 Nov; 33(11): 1282-7. PMid:23623745 https ://doi .org/10.101 $6 / j \cdot$ nedt. 2013.03 .020

[4] Lapena-Monux YR, Cibanal-Juan L, Orts-Cortes MI, et al. Nurse's experiences working with nursing students in a hospital: a phenomenological enquiry. Rev Lat Am Enfermagem. 2016 Jul; 24(e2788): 1-8. PMid:27463112 https ://doi.org/10.1590/15 $18-8345.1242 .2788$

[5] Morrison TL, Brennaman L. What do nursing students contribute to clinical practice? The perceptions of working nurses. Appl Nurs Res. 2016 Nov; 32: 30-5. PMid:27969047 https ://doi .org/10.101 6/j.apnr.2016.03.009

[6] Elsayes HA, Obied HK. Association between senior nursing students' perceived stress and learning environment in clinical practice. J Nurse Educ Pract. 2017 Nov; 8(3): 126-36. https://doi.org/10.543 0/jnep.v8n3p126

[7] Jack K, Hamshire C, Harris WE, et al. "My mentor didn't speak to me for the first four weeks": perceived unfairness experienced by nursing students in the clinical practice settings. J Clin Nurs. 2019 Mar; 27(5-6): 929-938. PMid:28815761 https ://doi.org/10.1 $111 /$ jocn. 14015

[8] Hyun MS, De Gagne JC, Park J, et al. Incivility experiences of nursing students in South Korea. Nurs Ethics. 2018 Mar: 25(2); 186-198. 
PMid:29529972 https://doi.org/10.1177/09697330166845 46

[9] Koontz AM, Mallory JL, Burns JA, et al. Staff Nurses and students: the good, the bad, and the ugly. Medsurg Nurs. 2010 Jul-Aug; 19(4): 240-4, 246

[10] Ahn YH, Choi J. Incivility experiences in clinical practicum education among nursing students. Nurse Educ Today. 2019 Feb; 73: 48-53. PMid:30504075 https://doi.org/10.1016/j.nedt.2018.11 .015

[11] Thomas CA. Stifled learning: nursing students experience of incivility in clinical education. 2018 Apr/Jun; 35(2): 106-111. PMid:29521907 https ://doi .org/10.1097/CNJ .0000000000 000477

[12] O'Nan CL, Jenkins K, Morgan LA, et al. Evaluation of Duffy's Quality of Caring Model. Int J Hum Caring. 2014; 18: 27-34. https ://doi.org/10.20467/1091-5710-18.1.27
[13] Clark CM. Creating and sustaining civility in nursing education: a faculty field guide. Sigma Theta Tau International; 2013.

[14] Tecza BM, Boots BK, Clay PM, et al. Development of an instrument to measure civil and uncivil behaviors in the hospital clinical environment for nurse leaders. J Nurs Adm. 2015 Jul-Aug; 5(7-8): 391-7. PMid:26204381 https://doi.org/10.1097/NNA.0000000000 000220

[15] Clark CM. Fostering a culture of civility and respect in nursing. J Nurs Reg. 2019 Apr; 10(1): 44-52. https ://doi.org/10.1016/ S2155-8256 (19) 30082-1

[16] Tezca BM, Boots B, Mains B, et al. Incivility toward nursing students in clinical interventions: measuring the incidence and testing interventions. J Nurs Adm. 2018 Nov; 48(11): 585-90. https : //doi.org/10.1097/NNA.0000000000000684

[17] 1Clark C. Why civility matters. Reflect Nurs Leadersh. 2010; 36(1). 